EVS27

Barcelona, Spain, November 17-20, 2013

\title{
Development of Regenerative Braking Co-operative Control System for Automatic Transmission-based Hybrid Electric Vehicle using Electronic Wedge Brake
}

\author{
Jiweon $\mathrm{Ko}^{1}$, Sungyeon $\mathrm{Ko}^{1}$, Yongsun Bak ${ }^{1}$, Mijeong Jang ${ }^{1}$, Byoungsoo Yoo ${ }^{2}$, \\ Jaeseung Cheon ${ }^{3}$, Hyunsoo Kim ${ }^{1}$ \\ ${ }^{I}$ School of Mechanical Engineering, Sungkyunkwan University, 300 Cheoncheon-dong, Suwon, 440-746, Korea, \\ rapkjw@nate.com \\ ${ }^{2}$ Hyundai Motor Company, 772-1 Jangduk-dong, Hwaseong, Gyeonggi-do, 445-706, Korea \\ ${ }^{3}$ Hyundai Mobis R\&D Center, 80-10 Youngin-si, 449-912, Korea
}

\begin{abstract}
This research proposes a regenerative braking co-operative control system for the automatic transmission (AT)-based hybrid electric vehicle (HEV). The brake system of the subject HEV consists of the regenerative braking and the electronic wedge brake (EWB) friction braking for the front wheel, and the hydraulic friction braking for the rear wheel. A regenerative braking co-operative control algorithm is suggested for the regenerative braking and friction braking, which distributes the braking torque according to the driver's demand. A vehicle test was performed to evaluate the proposed braking system and cooperative control algorithm.
\end{abstract}

Keyword : Regenerative braking, Electronic wedge brake(EWB), Co-operative control, Hybrid electric vehicles

\section{Introduction}

In hybrid electric vehicle's (HEV) braking, the regenerative braking can not be used only by itself due to the following reasons: 1) the regenerative braking force is not large enough to cover the driver's demanded braking force, 2) battery state of charge (SOC) limitation, 3) vehicle (motor) speed, etc [1][2]. Therefore, friction braking should be needed together with the regenerative braking and a control algorithm is required to ensure active co-operative control between the regenerative braking and friction braking[3][4].

This study proposes a co-operative control system of the regenerative braking for an automatic transmission (AT)-based HEV using the electronic wedge brake (EWB) on the front wheel, and the hydraulic brake on the rear wheel.
In addition, a regenerative braking co-operative control algorithm is suggested for the regenerative braking and friction braking. A vehicle test was performed to evaluate the proposed braking system and co-operative control algorithm.

\section{Regenerative braking system for AT-based HEV}

Figure 1 shows the regenerative braking system for the AT-based HEV in this study. The HEV is a front-wheel drive vehicle and performs regenerative and friction braking for front wheels and friction braking for rear wheels. The front wheels have a EWB, and the rear wheels, a hydraulic brake. The EWB that is used in this study generates a clamping force by using the selfreinforcing effect on the screw and wedge. This self-reinforcing effect can provide the much 
braking force with small actuator power[5]. The hydraulic brake of the rear wheels operates as follows: when a driver steps on the pedal and pushes the piston of the master cylinder, a pressure is formed in the master cylinder. This pressure is supplied to the rear wheel caliper through the hydraulic line and a clamping force is generated. Brake control unit (BCU) distributes the braking force to the front and rear wheel according to the driver's demand and the vehicle condition. The hybrid control unit (HCU) determines the amount of regenerative braking torque using the $\mathrm{BCU}$ signals and the gear shift information.

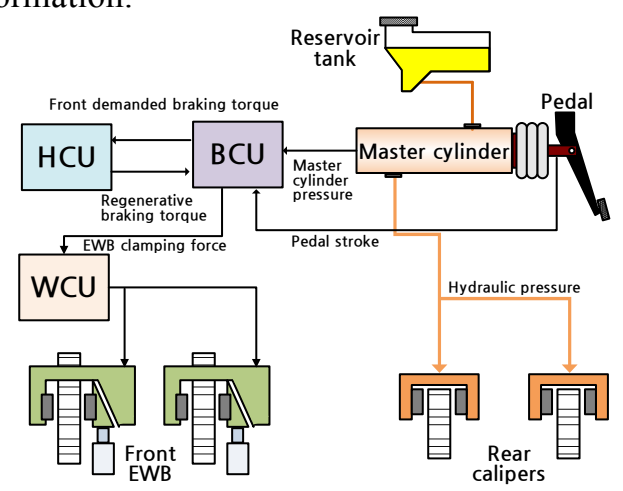

Figure 1 Regenerative braking co-operative control system for AT-based HEV

\section{Regenerative braking co- operative control algorithm}

Figure 2 shows the proposed regenerative braking co-operative control algorithm of this study. The subject vehicle of the study performs the rear friction braking at all section $(\mathrm{S}, \mathrm{T})$ through the master cylinder by the driver's brake pedal effort. The regenerative braking on the front wheel and the friction braking on the rear wheel are performed in the section S according to the co-operative control algorithm. The regenerative braking and the friction braking on the front wheel, and the friction braking on the rear wheel operate simultaneously in section $T$ where the demanded deceleration is larger than deceleration of section $\mathrm{S}$.

Figure 3 shows the characteristic map of the drive motor that is installed in the target vehicle. The maximum regenerative braking torque remains the same under the base rpm and decreases when the speed increases. Therefore, the amount of regenerative braking is determined as follows: When the motor speed is $\omega_{\mathrm{A}}$, if the front required braking torque $(\mathrm{A})$ is smaller than the maximum regenerative braking torque (B), the front wheel braking is performed only by the regenerative braking. At the motor speed of $\omega_{B}$, since the maximum regenerative braking torque (C) is smaller than the front required braking torque (A) and the required braking torque cannot be supplied with only regenerative braking, the insufficient braking torque for the front wheel braking is supplemented with friction braking. Thus, even for the braking in Section S in Figure 2, the regenerative and friction braking on the front wheels and the friction braking on the rear wheels may be performed depending on the motor speed. By the same principle, only the regenerative braking on the front wheels and the friction braking on the rear wheels may be performed in Section T.

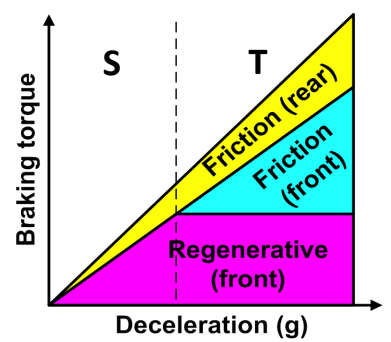

Figure 2 Regenerative braking co-operative control algorithm

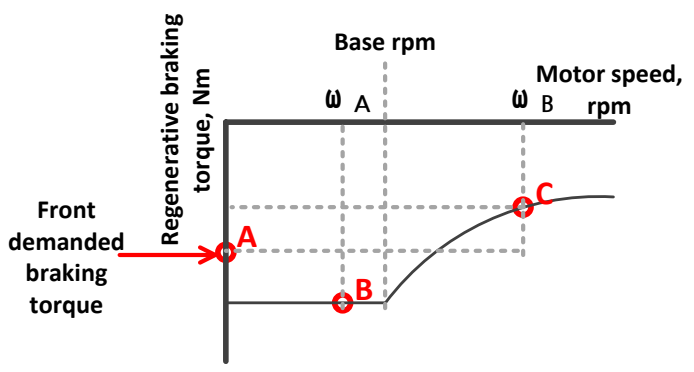

Figure 3 Motor characteristic map

\section{Vehicle test}

To evaluate the performance of the proposed regenerative braking co-operative control system, a vehicle test was performed with an AT-based HEV equipped with the developed braking system(Figure 1). Figure 4 shows a schematic diagram of regenerative braking co-operative control system for the target vehicle. The regenerative braking co-operative control algorithm composed with MATLAB Simulink was installed in the host PC which used DSP (digital signal processor) and CAN I/O to play the role of BCU.

When the driver steps on the brake pedal, the pedal stroke and the pressure of the rear-wheel master cylinder are measured and sent to the BCU, and the braking pressure generated from the rear-wheel 
master cylinder pushes the piston of the rearwheel caliper to generate friction braking force for rear wheels. The BCU determines the total demanded braking torque according to the pedal stroke and calculates the front demanded braking torque considering the pressure of the rear-wheel master cylinder. The front demanded braking torque is input to the $\mathrm{HCU}$ and the HCU determines the regenerative braking torque using the vehicle condition and sends it to the vehicle and the BCU. The BCU converts the front demanded braking torque minus the regenerative braking torque to the demanded clamping force of the EWB at the front wheel and sends it to the wedge control unit (WCU) which makes the EWB generate a clamping force according to the demanded clamping force.

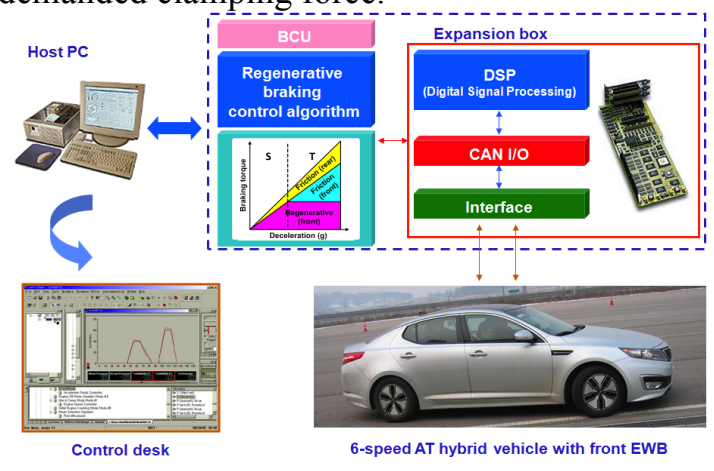

Figure 4 Schematic diagram of regenerative braking co-operative control system for target vehicle

\section{Experiment results and discussion}

The performance of the regenerative braking cooperative control system was evaluated for the deceleration braking of $0.3 \mathrm{~g}$ starting from $\mathrm{v}=100$ $\mathrm{km} / \mathrm{h}$.

Figure 5 shows the experimental results of the regenerative braking co-operative control algorithm. The braking pedal stroke (b) starts to increase at $\mathrm{t}=0.5 \mathrm{sec}$ and is maintained constant at $36 \mathrm{~mm}$. The pressure of the master cylinder starts to increase together with the braking pedal stroke and is maintained constant at 6 bars. The vehicle velocity (a) begins to decrease from 100 $\mathrm{km} / \mathrm{h}$ and becomes zero at 9.5 seconds. The automatic transmission gear (c) is at the 5th during the driving and when the braking begins, the gear is downshifted to 4th and 3rd and maintains the 1 st after stopping of the vehicle. The front demanded braking torque (d) increases in proportion to the braking pedal stroke and stays constant at $1812 \mathrm{Nm}$. The regenerative braking torque (d) starts to increase in section $\mathrm{O}$ and increases in section $\mathrm{P}$ according to the motor characteristic curve and the automatic transmission gear stage, and becomes constant in section Q. In section $\mathrm{N}$, regenerative braking torque is not generated because it takes time for $\mathrm{HCU}$ to calculate the regenerative braking torque after checking the transmission gear stage, the battery SOC and vehicle conditions. Instead, the EWB clamping force (e) increases to fill the insufficient front demanded braking torque in section $\mathrm{N}$ because there is no regenerative braking torque. The EWB clamping force increases in section $O$ and decreases in section $\mathrm{P}$ as the regenerative braking torque increases. In section Q, the EWB clamping force is constant because the regenerative braking torque is constant. The rear friction braking torque (d) is generated in section $\mathrm{N}$ and increases before staying constant at 205 $\mathrm{Nm}$. The deceleration (f) increases in the negative direction as the braking pedal stroke increases, before staying constant at $0.3 \mathrm{~g}$.

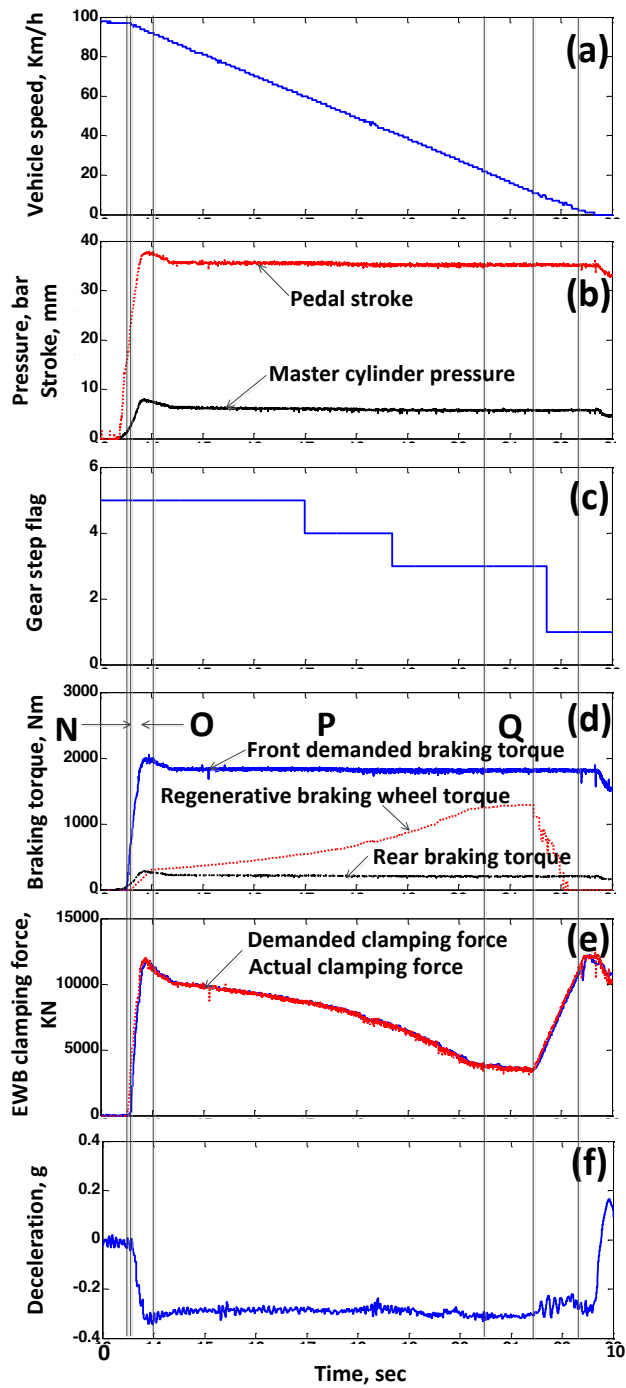

Figure 5 Experimental result (deceleration $=0.3 \mathrm{~g}$ ) 


\section{Conclusion}

This study proposed a regenerative braking cooperative control system which consists of EWB friction braking for front wheels and hydraulic friction braking for rear wheels. A co-operative control algorithm was suggested for the regenerative braking and friction braking, which distributes the braking torque according to the driver's demand. A vehicle test was performed to evaluate the proposed braking system and cooperative control algorithm. The results of the experiment show that the rear wheel braking was operated at all times through the master cylinder by the driver's brake pedal effort, and the front wheel braking were performed by the regenerative braking and EWB friction braking according to the co-operative control algorithm. The driver's demand for the braking force was satisfied through the co-operative control of the regenerative and friction braking.

\section{References}

[1] C. Albrichsfeld and J. Kamer, "Brake Syste $\mathrm{m}$ for Hybrid and Electric Vehicle", SAE International 2009-01-1217

[2] F. Sangtarash, V. Esfahanian, H. Nehzati, S. Haddadi, M. A. Bavanpour and B. Haghpanah "Effect of Different Regenerative Braking Strategies on Braking Performance and Fuel Economy in a Hybrid Electric Bus Employing CRUISE Vehicle Simulation", SAE International 2008-011561

[3] H. Yeo and H. Kim, "Hardware In the Loop Simulation of Regenerative Braking for a Hybrid Electric Vehicle", Journal of Automobile Engineering, Vol. 216, pp. 855864, No. 11, 2002

[4] Y. Gao, L. Chen and M. Ehsani, "Investigation of the Effectiveness of Regenerative Braking for EV and HEV", SAE, 1999-01-2910, 1999

[5] C. Jo, S. Lee, H. Song, Y. Cho, I. Kim, D. Hyun and H. Kim, "Design and Control of an Upper-Wedge-Type Electronic Brake ", Journal of Automobile Engineering, Vol. 224, pp. 1393-1405, No. 11, 2010

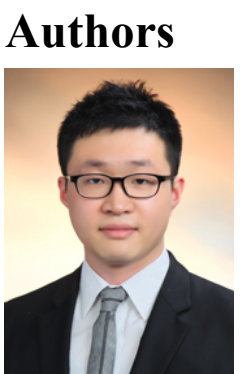

Jiweon Ko received B.S in mechanical engineering from Sungkyunkwan University, Suwon, Korea, in 2009, where he has been working towards $\mathrm{Ph}$. D. degree. His research interests include modeling of electronic brake system and control of regenerative braking for hybrid electric vehicle.

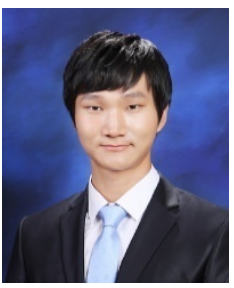

Sungyeon Ko received B.S and M.S in mechanical engineering from Sungkyunkwan University, Suwon, Korea, in 2010 and 2012, where he has been working towards $\mathrm{Ph}$. D. degree. His research interests include modeling and control of in-wheel vehicle.

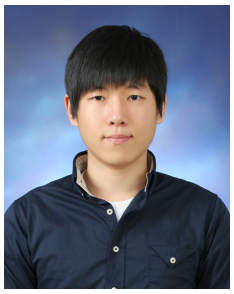

Yongsun Bak received the B.S. degrees in mechanical engineering from Sungkyunkwan University, Suwon, Korea, in 2013, where he has been working towards the M.S. degree. His research interests include the modeling and control of hybrid electric vehicle.

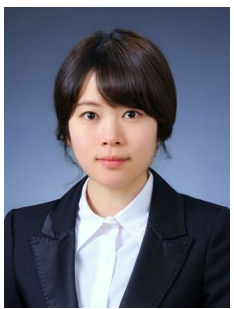

Mijeong Jang received the B.S. degrees in mechanical engineering from Sungkyunkwan University, Suwon, Korea, in 2013, where he has been working towards the M.S. degree. His research interests include the modeling and control of hybrid electric vehicle.

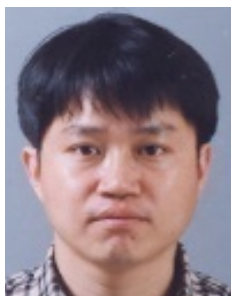

Byoungsoo Yoo received his B.S. degree in mechanical engineering from Inha University, Incheon, Korea, in 1988. His research interests include the design of brake system. Since 1990, he has worked in chassis engineering team in Hyundai-Kia R\&D Center.

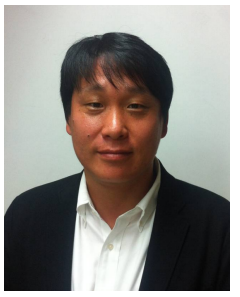

Jaeseung Cheon received his Ph.D. degree in mechanical engineering from the Korea Advanced Institute of Science and Technology (KAIST) in 2003. He has been working at MOBIS since 2004 in advanced development of braking systems and in-wheel motor systems and is currently a chief engineer in the Brake System Design Team. 


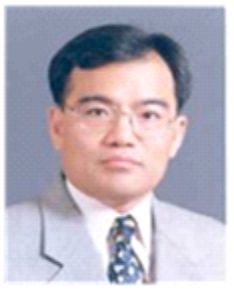

Hyunsoo Kim received a B.S. in mechanical engineering from Seoul National University, Seoul, Korea, in 1977, a M.S. degree in mechanical engineering from the Korea Advanced Institute of Science and Technology (KAIST), Seoul, Korea, in 1979, and a Ph.D. degree in mechanical engineering from the University of Texas at Austin, Texas, USA, in 1986.

Since 1986, he has worked as a Professor, Chairman, and Dean of the College of Engineering at Sungkyunkwan University. His main research interests include Hybrid Electric Vehicle (HEV) transmission system design, regenerative braking, and optimal power-distribution algorithms for HEV and vehicle stability control for HEV and In-wheel Electric Vehicles. He has authored numerous journal papers and patents.

Prof. Kim is a Division President of Electric Drive Vehicle of the Korea Society of Automotive Engineers and an editor of the International Journal of Automotive Technology. He has served the society as a leader in next-generation automotive technology in Korea. 